\title{
Membrane Autopsy of a 10 year old hollow fibre membrane from Sydney Olympic Park water reclamation plant
}

\author{
S. Phuntsho ${ }^{\mathrm{a}}$, A. Listowski ${ }^{\mathrm{a}}$, H.K Shon ${ }^{\mathrm{a},{ }^{*}}$, P. Le-Clech ${ }^{\mathrm{b}}$, S. Vigneswaran ${ }^{\mathrm{a}}$, \\ ${ }^{a}$ School of Civil \& Environmental Engineering, University of Technology Sydney (UTS), Broadway, \\ New South Wales, 2007, Australia \\ ${ }^{b}$ UNESCO Centre for Membrane Science and Technology, University of New South Wales, Sydney, \\ Australia
}

*Corresponding author: hkshon@eng.uts.edu.au, Tel: +61 29514 2629, Fax: +61 295142633

\begin{abstract}
Membrane autopsy was performed for a 10 year old polypropylene (PP) hollow fibre microfiltration membrane from Sydney Olympic Park water reclamation plant. The properties of the membrane were studied using scanning electron microscope (SEM) imaging, contact angle, bubble test, thermogravimetric analysis, tensile strength test and functional group. The old and fouled membrane exhibited a significant difference in surface properties and material strength in comparison to the virgin membrane. The old and fouled membrane surface is less hydrophilic and less negatively charged indicating that aged membrane is more vulnerable to fouling than virgin membrane. The fibre material of the old fouled membrane appears less flexible and brittle. Foulant analysis indicated that major components of the metallic elements were silicon and calcium. The dissolved organic matter was mainly composed of biopolymers (hydrophilic) and humic substances (hydrophobic).
\end{abstract}

Keywords: Membrane fouling, membrane autopsy, organic and inorganic foulant, hollow fibre membrane 


\section{Introduction}

Membrane processes are used to accomplish a separation since the membrane has the ability to transport one component more readily than another (Mulder 1997). Membrane filtration is nowadays becoming an indispensable technology for water \& wastewater purification however, membrane fouling is one of the most serious challenges (Amy 2008) and also considered an inevitable consequence of filtration processes (Belfort et al. 1994; Singh and Song 2005). Membrane fouling results in the reduction of permeate flux and increases operating pressures ultimately affecting the energy requirements and the plant economy (Darton et al. 2004; Nghiem and Schäfer 2006). Numerous engineering and manufacturing techniques have been developed to reduce the effect of membrane fouling some of which include improving the properties to make membrane more fouling resistant, optimising various operational parameters, pretreatment of feed water through various processes, backwashing of membrane, physical and chemical cleaning of membranes, addition of anti-fouling or anti-scaling agents, etc.

Although it is true that most of these efforts have facilitated in combating membrane fouling problems to certain extent, physical and chemical cleaning can also directly impact on the life of the membrane due to prolonged stresses endured by the membrane. One way of understanding how and why the performance of the membrane decline in the long run, is to perform a membrane autopsy study. It could provide a reliable understanding of how the properties of the membrane deteriorate in the long run due to repeated physical and chemical exposures. Membrane autopsy is also a reliable method for determining the true identity of the membrane foulant based on which further recommendations for pretreatment and cleaning methods can be made with confidence (Darton et al. 2004). 
In this study, we report the autopsy of a hollow fibre microfiltration (MF) membrane which has been in operation for the last ten years at the Sydney Olympic Park (SOP) water reclamation plant (WRP). While we identified and characterised the major constituents of the membrane foulant, this study focused on the properties of the membrane. The authors are of the opinion that, during the last 10 years of its operation, the membrane has been subjected to feedwater which might have considerably varied in characteristics depending on the seasons and therefore a study on the foulant would in fact represent the characteristics for feed water that might have been used for short duration before the membrane was removed for autopsy. Membrane characteristics affect the performance of the membrane in terms of rejection rate and flux (Bellona et al. 2004). A fouled membrane surface can exhibit different characteristics to its original surface which may either improve or degrade the rejection properties of the membrane (Xu et al. 2006).

\section{Overview of case study area}

SOP is located at Homebush bay, one of the suburbs of Sydney, under New South Wales State of Australia. Built on the former landfill site, the construction of the park was completed in 2000 to host the World Olympic 2000. Occupying an area of about 640 hectares, it includes many entertainment and sporting complexes and also houses many corporate and commercial offices. The Park has a locally integrated approach to water conservation based on stormwater reuse, wastewater reprocessing and water demand reduction. According to SOP authority (2008), Water Reclamation and Management Scheme (WARMS) was an important environmental initiative of the Sydney's Olympic bid commitment to maximise the use of recycled water. WRAMS is a large scale integrated urban water system incorporating collection, storage and treatment of sewage and 
stormwater for recycling for non-potable uses to all residents, commercial premises and sporting venues. WRAMS has played a major role in the protection of local waterways and helped maintain a sustainable supply of drinking water since its commencement in July 2000.

The WRP consists of MF and reverse osmosis (RO) processes. The feed water for the WRP consists of biologically treated (sequencing batch reactor) secondary effluent from the wastewater treatment plant located within the SOP and the storm water retention at Brickpit pond. The feed water first flows to the buffer tank which is then processed by hollow fibre microfiltration system (US Filter-Memcor). A portion of the effluent from MF is sent directly to the water reclamation tank while the rest is used for RO desalination to lower the conductivity before sending to the reclamation tank. The reclaimed water is used for nonpotable purposes such as park irrigation, park water features, toilet flushing, pavement cleaning, etc. The WRP is designed to produce 7.5 megalitres per day (MLD) of filtered water (CMF) and 2.0 MLD of desalinated water (RO). The plant is designed to treat mixture of secondary effluent from a biological sewage treatment plant and the surface storm water runoff from Brick-pit storage. The plant is fully automated and runs 24 hours a day.

MF unit runs at a constant preset flow rate and the day's flow rate is predetermined as per the water requirement. Flow control is achieved by modulating butterfly valve, controlled by a controller. The MF is periodically backwashed initiated automatically when TMP exceeds the predetermined level or every 45 minutes whichever occurs first. Backwash cycle forces compressed air through the wall of the membrane from inside to out to dislodge the foulant build up. Raw water flows through the modules from bottom to top, carrying the dislodged 
particles to the backwash outlets. Chemical cleaning is performed fortnightly using EX-A3 chemical (caustic 50\% plus wetting agents). Figure 1 shows the WRP, its facilities.

\section{Figure 1: WARMS facility at Sydney Olympic Park}

\section{Materials and Methods}

The study has been divided into two parts: membrane and foulant characterisation. This membrane has been in operation for last 10 years and this means that the feedwater characteristics must have been altered for many times depending on the local weather and climatic conditions. It is felt that, the test on membrane properties may yield more significant information than the test on the membrane foulant which may reflect the short term characteristics of the feed water used before the membrane was removed for replacement. Therefore, more attempts are made on the characterisation of membrane than the foulant.

\subsection{Collection of hollow fibre membrane}

Table 1 shows the information related to the feed water characteristics and the hollow fibre membrane module. The MF module samples were collected when they were being removed and replaced with the new MF modules. The membrane modules were stored in the cold storage at about $3^{\circ} \mathrm{C}$ before conducting the membrane autopsy.

Table 1: Information related to typical feed water characteristics (sampling on 27/01/2010) and the membrane module (Source SOPA) 


\subsection{Characterisation of hollow fibre membrane}

Three different polypropylene (PP) fibre samples were used for studying the membrane properties comparatively: fouled fibre as removed from the membrane module, fouled fibre cleaned by chemical solution and the virgin fibre. The fouled membrane was cleaned by soaking the fibre in $0.1 \mathrm{~N} \mathrm{NaOH}$ for 24 hours and then in ultra sonication bath for 30 minutes. Visual analysis of the membrane surface was carried out using high resolution field emission scanning electron microscope (Zeiss Supra 55VP SEM with Raith E-beam Lithography System \& HKL EBSD). The bubble point text was carried out to study the pore characteristics of the hollow fibre membrane using Capillary Flow Porometer (model CFP1200-AEXL, PMI Porous Materials Inc.) under the dry-up/wet-up test mode. Zeta potential of the fibre was measured using electrokinetic streaming potential analyser (SurPASS electrokinetic analyser, Anton Paar). Tensile test of the fibre material was carried out using Instron 4302 tensile testing equipment (Instron Pvt. Ltd. Australia). Test was carried out on samples length of $350 \mathrm{~mm}$ at load cell and loading rate at $10 \mathrm{~N}$ and $50 \mathrm{~mm} / \mathrm{min}$ respectively. Contact angle measurement was carried out by goniometrically determining the angle from observation of the three-phase meniscus system using contact angle goniometer (Rame Hart, Nodel 100), described elsewhere (Khulbe et al. 2003).Thermo-gravimetric tests (TGA) in this study were performed using Thermal Advantage ${ }^{\circledR}$ device (Universal TA Instruments). The fibre samples were dried prior to testing to prevent the presence of moisture in the samples. Analysis was done in inert atmosphere ( $\mathrm{N}_{2}$ gas), with temperature increase in the

range of $20-750^{\circ} \mathrm{C}$. Ramp test method was used where at a temperature increase of $20^{\circ} \mathrm{C} / \mathrm{min}$. Infrared Spectroscopy was carried out using a digilab Stingray System, comprising of a FTS 7000 FT-IR spectrometer, coupled with an UMA 600 infrared microscope with a 
lancer 64x64 focal plane array (FPA) detector. Spectra were collected and processed with digilab Winpro Software.

\subsection{Foulant Extraction and Characterization}

The membrane was divided into 3 sections: inlet, middle and outlet section and the fibres were cut separately. The fibres were soaked in $0.1 \mathrm{~N} \mathrm{NaOH}$ or $0.1 \mathrm{~N} \mathrm{HCl}$ solutions and left on the shaker at 100 RPM for 24 hours. The fibre was then untrasonicated for 30 minutes before removing the fibres from the solution to collect the dissolved foulant. The $\mathrm{pH}$ of the samples was adjusted using $0.1 \mathrm{~N} \mathrm{NaOH}$ or $\mathrm{HCl}$. The foulant samples were then analysed into its different constituents using different analytical tools.

Dissolved organic carbon (DOC) was measured using TOC-VCPH (TNM-1) (Shimadzu, Japan) while LC-OCD (Germany). Organic matter was identified and classified using LC-OCND (Model 8, DOC-Labor, Germany). All samples were pre-filtered with $0.45 \mu \mathrm{m}$ filter. Inorganic elements were analysed by inductively coupled plasma mass spectrometry (ICP-MS) (7500cs, Agilent, USA) as per APHA (2005).

\section{Results and Discussions}

\subsection{Membrane characterization}

The membrane module appeared significantly fouled at the inlet portion of the module than at the middle and the outlet (Figure 1.d). The SEM images of the fibre samples are shown in Figure 2. Foulant deposits some of which appeared like scale formation was observed on the fibre (Figure 2a). After the fouled fibre was cleaned by $\mathrm{NaOH}$ solution, a number of spots or patches were observed (Figure 2.b). These patches are likely a result of the change in the 
surface of the membrane due to deposits of irreversible foulant. These patches were not visible with the virgin membrane (Figure $2 c$ ) where it appeared clean and quite smooth in surface. Bio-fouling could not be conducted immediately due to lack of facilities at the time of collection of the membrane samples.

The bubble point test was carried out to determine the average pore size of the hollow fibre as well as to detect any leakage along the membrane fibre. The average pore size of the virgin membrane was observed close to its nominal value of $0.241 \mu \mathrm{m}$ at a bubble point pressure of 1.9 bars. However the bubble test with the fouled membrane failed with the instrument probably because the membrane pores were perhaps chocked with the foulant deposits.

\section{Figure 2: SEM images of hollow fibre PP membrane samples}

Contact angle is an important parameter for determining the hydrophobic or hydrophilic properties of a membrane surface (Northcott et al. 2009). The contact angles for all cases were more than $30^{\circ}$. Generally a water droplet exhibits a contact angle between 0 and $30^{\circ}$ on a hydrophilic surface and larger than $30^{\circ}$ are considered hydrophobic in nature. Figure 3 shows the contact angles of the fouled fibre, the fouled fibre after cleaning and the virgin fibre. The contact angle of the fouled membrane was higher than the virgin membrane which is likely due to the presence of foulant deposits on the membrane surface. After the foulant was removed by $\mathrm{NaOH}$ cleaning, the contact angle slightly decreased however it remained still higher than the virgin membrane. The increase in the contact angle of the fibre is an indication of the membrane losing its hydrophilic property and therefore more susceptible to fouling than the virgin membrane. 
Zeta potential of the membrane fibre is shown in Figure 4. The results indicate that the zeta potential of the fouled membrane is less negative when compare to the virgin membrane. the Zeta potential of all the fouled membranes are generally found less negative (Soffer et al. 2002). The decrease in zeta potential of the membrane reduces the net repulsive force (increases attractive force) between the membrane surface and the foulant specimens (which are usually negatively charged) resulting in higher fouling of the membrane. It has been reported that, the foulant layer weakens the electrokinetic flow owing to lower permeate flux, leading to decrease in membrane zeta potential (Chun et al. 2002).

Figure 3: Contact angle of hollow fibre membrane

\section{Figure 4: Zeta potential of the hollow fibre membrane}

In the last 10 years, the membrane has been subjected to constant physical force and chemical exposure. Backwashing involved a surge of pressurised or compressed air during which the water is forced from inside of the fibre (lumen) to outside to dislodge the particle build-up during the filtration process. During the backwashing process, the membrane fibre has been subjected to fluctuations in pressure and vibrations. The fibres are also subjected to significant local shear forces due to vibrations that arise during start-up and shut-down and upon the transition from cleaning to filtration and vice versa. Moreover, the membrane fibres are also subjected to repeated chemical cleaning once every 2 weeks or more frequently depending on the quality of feed water. During chemical cleaning process, membrane fibre materials are not only exposed to chemical attack but also subjected to physical shear and vibrations. All these physical forces acting on the membrane and chemical exposure repeatedly could undermine the strength of the materials and its integrity. Repeated physical force subjected to membrane fibre may result in material 
fatigue and damage on the fibre material. Long term exposure to chemical cleaning agents may deteriorate the strength of the materials.

Tensile strength is directly related to the material properties of the membrane and therefore the tensile test was carried out to evaluate the mechanical strength of the membrane material. The results in Table 2 show that the maximum elongation for the fouled membrane fibre is much lower than the virgin fibre indicating that, as the membrane ages under constant physical forces and chemical attacks, it becomes more brittle or less flexible and therefore more susceptible to membrane integrity problems.

Table 2: Results of the tensile test of the hollow fibre membranes. Length of the all the fibre samples were $350 \mathrm{~mm}$.

Figure 5 shows the degradation behaviour of a virgin and fouled PP hollow fibre membrane. The virgin PP fibre exhibited maximum degradation rate at $530^{\circ} \mathrm{C}$, while the fouled fibre and the fouled fibre after cleaning exhibited maximum degradation rates at much lower temperatures of $485^{\circ} \mathrm{C}$ and $495^{\circ} \mathrm{C}$ respectively indicating that the old PP membrane fibre has lower thermal stability than the virgin PP fibre. The degradation rates at these temperatures were much higher and narrower for virgin fibre than the fouled fibre due to absence of other impurities in the virgin material. The fouled fibre showed a much broader and multiple distribution of degradation peak due to the presence of contaminants of different compounds. The percentage mass loss at $500^{\circ} \mathrm{C}$ of heating was only $13 \%$ for virgin fibre while fouled fibre and fibre after cleaning exhibited much higher mass loss of $53 \%$ and $38 \%$ respectively.

Figure 5: Comparison of thermal degradation of PP hollow fibre membrane samples 
FTIR spectroscopy is used to study the characteristics the chemical structure of the PP membrane surface (Bae et al. 2001). FTIR spectra for PP hollow fibre membrane in Figure 6 showed a very similar absorbance for the old fouled fibre and old fibre after $\mathrm{NaOH}$ cleaning with the virgin PP fibre. The only unique observation was the small and broad absorbance spectrum between wave number 3100 and 3600 for the two old fouled PP fibres which was not a characteristic of the virgin fibre. This is likely due to the presence of foulant organic species on the membrane surface. Polysaccharides with significant number of hydroxyl group can exhibit a broad rounded absorption band above $3000 \mathrm{~cm}^{-1}$ (Howe et al. 2002).

Figure 6: FT-IR spectroscopy of PP hollow fibre membrane samples

\subsection{Foulant Characterization}

\subsubsection{Identification of major foulant compositions}

Table 3 shows the different components of the membrane foulant extracted from the hollow fibre membranes using $\mathrm{NaOH}$ and $\mathrm{HCl}$ solutions from inlet, middle and outlet portion of the membrane module (refer to Figure 1.d). $\mathrm{NaOH}$ solution was more effective in extracting organic foulant while $\mathrm{HCl}$ was more effective in extracting inorganic components. The foulant at the inlet portion of the membrane contained more organic carbon while the foulant at the outlet contained more inorganic carbon. Total nitrogen was also significant at the inlet portion indicating the presence of more organic fouling at the inlet region of the membrane module.

Silicon formed the highest fraction of metallic elements present in the membrane foulant likely due to silt and other soil debris in the stormwater run off from the local catchments. Calcium was the second highest fraction of metallic elements. Calcium $\left(\mathrm{Ca}^{2+}\right)$ is one of the 
most common and important multivalent cations, and its complexation with natural organic matter such as humic substances results in a highly compacted fouling layer and flux decline has been long studied (Clark and Lucas 1998; Yuan and Zydney 2000; Li and Elimelech 2004; Oschmann et al. 2005). The next highest metallic content was magnesium followed by potassium. Although other metals such as aluminum, iron and manganese were present in the foulant, their proportion was not significant.

Table 3: Components of foulants extracted from different regions of the membrane module

Liquid chromatography - organic carbon, nitrogen detection (LC-OCND) allows the fractionation of the organic matters and their detailed characterisation using organic carbon and nitrogen detectors (OCND). Table 4 shows the various components of DOC present in the membrane foulant extracted from various parts of the membrane module as analysed by LC-OCD. The DOC as expected is much higher at the inlet portion of the membrane module than the middle and the outlet region. DOC had consistently higher hydrophilic component with as high as $98 \%$ at the inlet region, $95 \%$ at the middle and $93 \%$ at the outlet. These results indicate that, hydrophilic components of the organic matter are mostly responsible for fouling off hollow fibre membrane fouling. The hydrophilic carbon was composed of bio-polymers (23-50\%), humic substances (26-40\%), building blocks (7-12\%) and low molecular weight neutrals (10-21\%). Hydrophilic compounds are poorly rejected by the membrane (Bellona et al. 2004) and therefore it is likely that they are adsorbed more on the membrane pores as foulant during the filtration process. Fan et al. (2001) also reported similar findings. A typical LC-OCD chromatogram is presented in Figure 7. 
Table 4: LC-OCD results of foulants extracted from different parts of the membrane. Nomenclature for M1 to M11 can be referred in Table 3

Figure 7: LC-OCD chromatogram of a typical foulant sample extracted from the membrane fibres

\section{Conclusions}

A membrane autopsy was conducted on a 10 year old PP hollow fibre MF membrane collected. The fouled PP membrane was studied comparatively with the virgin PP fibre membrane. SEM images indicated a significant difference in the appearance of the fouled fibre, fouled fibre after cleaning and the virgin surface. A number of spots or patches were observed on the fouled fibre after chemical cleaning which is likely a result of the change in the surface of the membrane due to deposits of irreversible foulant. The contact angles indicated that the PP membrane generally remained hydrophilic but slightly reduces its hydrophilic properties with age. Zeta potential of the fouled membrane was slightly higher than the virgin membrane, and the decrease in the net repulsive force between the membrane surface and the foulant could make membrane more susceptible to membrane fouling. Bubble test failed to determine the pore size of the fouled fibre even after chemical cleaning, indicating a much lower pore size due to irreversible deposits within the membrane pores. Tensile strength indicates that the PP fibre has become less flexible and more brittle when compared to virgin membrane likely due to long term exposure of fibre to fluctuations in hydraulic forces and to chemical cleaning agents. The fouled PP membrane also indicated reduced thermal stability. Foulant analysis indicated that major components 
of the metallic elements were silicon and calcium. The dissolved organic matter was mainly composed of hydrophilic components.

\section{Acknowledgements}

This study was funded by an ARC grant.

\section{References}

Amy, G. (2008). "Fundamental understanding of organic matter fouling of membranes." Desalination 231(2008): 44-51.

APHA (2005). Standard methods for the examination of water and wastewater: 21 st Ed. APHA and AWWA.

Bae, B., B. H. Chun, et al. (2001). "Surface characterization of microporous polypropylene membranes modified by plasma treatment." Polymer 42(18): 7879-7885.

Belfort, G., R. H. Davis, et al. (1994). "The behavior of suspensions and macromolecular solutions in crossflow microfiltration." J. Memb. Sci. 96(1-2): 1-58.

Bellona, C., J. E. Drewes, et al. (2004). "Factors affecting the rejection of organic solutes during NF/RO treatment-a literature review." Water Res. 38: 2795-2809.

Chun, M. S., H. I. Cho, et al. (2002). "Electrokinetic behavior of membrane zeta potential during the filtration of colloidal suspensions." Desalination 148(2002): 363-367.

Clark, M. M. and P. Lucas (1998). "Diffusion and partitioning of humic acid in a porous ultrafiltration membrane." J. Memb. Sci. 143(1-2): 13-25. 
Darton, T., U. Annunziata, et al. (2004). "Membrane autopsy helps to provide solutions to operational problems." Desalination 167(2004): 239-245.

Fan, L., J. L. Harris, et al. (2001). "Influence of the characteristics of natural organic matter on the fouling of microfiltration membranes." Water Res. 35(18): 4455-4463.

Howe, K. J., K. P. Ishida, et al. (2002). "Use of ATR/FTIR spectrometry to study fouling of microfiltration membranes by natural waters." Desalination 147(1-3): 251-255.

Khulbe, K. C., C. Feng, et al. (2003). "Characterization of polyethersulfone-polyimide hollow fiber membranes by atomic force microscopy and contact angle goniometery." $\underline{J}$ Memb. Sci. 226(1-2): 63-73.

Li, Q. and M. Elimelech (2004). "Organic Fouling and Chemical Cleaning of Nanofiltration Membranes:â€\%o Measurements and Mechanisms." Environ. Sci. Technol. 38(17): 4683-4693.

Mulder, M. (1997). Basic principles in membrane technology, Kluwer Academic Publishers. Nghiem, L. D. and A. I. Schäfer (2006). "Fouling autopsy of hollow-fibre MF membranes in wastewater reclamation." Desalination 188(2006): 113-121.

Northcott, K., S. E. Kentish, et al. (2009). "Development of membrane testing protocols for characterisation of RO and NF membranes." Desalination 236(2009): 194-201.

Oschmann, N., L. D. Nghiem, et al. (2005). "Fouling mechanisms of submerged ultrafiltration membranes in greywater recycling." Desalination 179(1-3): 215-223.

Singh, G. and L. Song (2005). "Quantifying the effect of ionic strength on colloidal fouling potential in membrane filtration." J. Colloid Interface Sci. 284(2): 630-638.

Soffer, Y., J. Gilron, et al. (2002). "Steaming potential and SEM-EDX study of UF membranes fouled by colloidal iron." Desalination 146(2002): 115-121.

SOP (2008). Sydney olympic park - Annual report 2007-2008. 
Xu, P., J. E. Drewes, et al. (2006). "Effect of Membrane Fouling on Transport of Organic Contaminants in Nf/Ro Membrane Applications." J. Memb. Sci. 279(1-2): 165-175.

Yuan, W. and A. L. Zydney (2000). "Humic Acid Fouling during Ultrafiltration." Environ. Sci. Technol. 34(23): 5043-5050. 


\section{Contents of Table}

Table 1: Information related to typical feed water characteristics (sampling on 27/01/2010) and the membrane module (Source SOPA)

Table 2: Results of the tensile test of the hollow fibre membranes. Length of the all the fibre samples were $350 \mathrm{~mm}$.

Table 3: Components of foulants extracted from different regions of the membrane module

Table 4: LC-OCD results of foulants extracted from different parts of the membrane. Nomenclature for M1 to M11 can be referred in Table 3 
Table 1: Information related to typical feed water characteristics (sampling on 27/01/2010) and the membrane module (Source SOPA)

\begin{tabular}{ll|ll}
\hline \multicolumn{1}{c|}{ Feed water characteristics } & \multicolumn{2}{c}{ Membrane module information } \\
\hline $\mathrm{pH}$ & 8.0 & Type & Hollow fibre MF \\
Temperature & $20-28^{\circ} \mathrm{C}$ & Pore size (nominal) & $0.2 \mu \mathrm{m}$ \\
Alkali $\left(\mathrm{CaCO}_{3}\right)$ Bicarbonate & $210(\mathrm{mg} / \mathrm{l})$ & Total modules & $270 \mathrm{Nos}$ \\
Turbidity & $4-50 \mathrm{NTU}$ & No. of fibres in each module & 20,000 \\
Conductivity & $800-1500 \mu \mathrm{S} / \mathrm{cm}$ & TMP & $20-80 \mathrm{kPa}$ \\
$\mathrm{BOD}$ & $5.0 \mathrm{mg} / \mathrm{l}$ & Internal dia of fibre & $0.3 \mathrm{~mm}$ \\
$\mathrm{COD}$ & $47 \mathrm{mg} / \mathrm{l}$ & Outer dia of fibre & $0.6 \mathrm{~mm}$ \\
Ammonia & $1.0 \mathrm{mg} / \mathrm{I}$ & Fibre material & Polypropylene-PP \\
Nitrite & $0.49 \mathrm{mg} / \mathrm{I} \mathrm{N}$ & Module installation & July 2000 \\
Nitrate & $0.12 \mathrm{mg} / \mathrm{I} \mathrm{N}$ & Feed temperature range & $2-40{ }^{\circ} \mathrm{C}$ \\
Total Nitrogen & $3.0 \mathrm{mg} / \mathrm{I} \mathrm{N}$ & Max cleaning solution temp & $40{ }^{\circ} \mathrm{C}$ \\
Total Phosphate & $1.7 \mathrm{mg} / \mathrm{I} \mathrm{N}$ & Max B/wash back pressure & $5 \mathrm{kPa}$ \\
\hline
\end{tabular}


Table 2: Results of the tensile test of the hollow fibre membranes. Length of the all the fibre samples were $350 \mathrm{~mm}$.

\begin{tabular}{lccc}
\hline \multicolumn{1}{c}{ Samples } & Breaking Force $(\mathrm{N})$ & Stress (Mpa) & Elongation $(\mathrm{mm})$ \\
\hline Virgin fibre & 1.6 & 7.3 & 334.4 \\
Fouled fibre & 1.5 & 10 & 266.3 \\
Fouled fibre cleaned & 0.6 & 3.8 & 102.7 \\
\hline
\end{tabular}


Table 3: Components of foulants extracted from different regions of the membrane module

\begin{tabular}{|c|c|c|c|c|c|c|c|c|}
\hline Parameters $\downarrow$ Sample I.D $\rightarrow$ & M1 & M2 & M4 & M5 & M7 & M8 & M10 & M11 \\
\hline Module portion & \multicolumn{2}{|c|}{ Inlet portion } & \multicolumn{2}{|c|}{ Middle portion } & \multicolumn{2}{|c|}{ Outlet portion } & \multicolumn{2}{|c|}{ Whole module } \\
\hline Extraction using & $\mathrm{NaOH}$ & $\mathrm{HCl}$ & $\mathrm{NaOH}$ & $\mathrm{HCl}$ & $\mathrm{NaOH}$ & $\mathrm{HCl}$ & $\mathrm{NaOH}$ & $\mathrm{HCl}$ \\
\hline Dissolved Organic Carbon (mg/L) & 40.0 & 16.5 & 19.7 & 7.7 & 17.7 & 4.9 & 95.0 & 40.9 \\
\hline Inorganic Carbon (mg/L) & 30.0 & 8.9 & 16.2 & 0.9 & 74.7 & 2.5 & 21.5 & 12.9 \\
\hline Total Carbon (mg/L) & 70.0 & 25.4 & 35.9 & 8.6 & 92.4 & 7.4 & 116.5 & 53.8 \\
\hline Zeta potential & -14.9 & -7.4 & -9.2 & -4.2 & -8.5 & -5.2 & -15.2 & -5.4 \\
\hline Total nitrogen (mg/L N) & 19.83 & 18.25 & 6.10 & 3.16 & 7.29 & 3.42 & 67.21 & 32.93 \\
\hline Ammonia (mg/L N) & 4.32 & 3.67 & 1.78 & 1.09 & 2.19 & 0.79 & 13.40 & 9.04 \\
\hline Total Phosphorus (mg/L P) & 2.05 & 31.70 & 0.45 & 0.58 & 0.59 & 0.63 & 71.79 & 27.60 \\
\hline Orthophosphate (mg/L P) & 0.69 & 21.01 & 0.25 & 0.01 & 0.28 & 0.02 & 37.94 & 7.00 \\
\hline Total suspended solids (mg/L) & 113 & 234 & 23 & 98 & 99 & 28 & 327 & 489 \\
\hline Potassium (mg/L) & 12.8 & 3.7 & 1.4 & 1.2 & 1.4 & 1.1 & 6.3 & 7.4 \\
\hline Calcium (mg/L) & 5.0 & 76.0 & 3.8 & 7.9 & 3.9 & 6.8 & 112.4 & 171.7 \\
\hline Magnesium (mg/L) & 3.1 & 8.9 & 1.3 & 2.8 & 0.9 & 2.5 & 17.0 & 50.6 \\
\hline Silicon (mg/l) & 10.3 & 16.3 & 9.5 & 13.2 & 7.1 & 10.1 & 119.2 & 132.1 \\
\hline Aluminium (mg/L) & 0.94 & 0.24 & 0.73 & 0.20 & 0.77 & 0.02 & 0.63 & 0.11 \\
\hline $\operatorname{Iron}(\mathrm{mg} / \mathrm{L})$ & 0.52 & 0.11 & 0.33 & 0.04 & 0.36 & 0.01 & 0.97 & 0.10 \\
\hline Manganese (mg/L) & 0.17 & 0.42 & 0.06 & 0.13 & 0.06 & 0.13 & 0.49 & 0.25 \\
\hline Bicarbonate $\left(\mathrm{mg} / \mathrm{L} \mathrm{CaCO}_{3}\right)$ & 206 & 110 & 82 & 18 & 313 & 18 & 175 & 78 \\
\hline Sulfate $\left(\mathrm{mg} / \mathrm{L} \mathrm{SO}_{4}{ }^{2-}\right)$ & 74 & 51 & 36 & 25 & 46 & 16 & 120 & 81 \\
\hline
\end{tabular}

1. Dissolved metals - samples filtered through $0.45 \mu \mathrm{m}$ cellulose acetate and then acidified with nitric acid prior to analysis

2. Metals/ salts analysed by ICP-MS (Inductively Coupled Plasma - Mass Spectrometry)

3. Analysis performed according to APHA, 2005, "Standard Methods for the Examination of Water \& Wastewater",

21st Edition, except where stated otherwise. 
Table 4: LC-OCD results of foulants extracted from different parts of the membrane. Nomenclature for M1 to M11 can be referred in Table 3

approximate molecular weights $(\mathrm{g} / \mathrm{mol})$.

\begin{tabular}{|c|c|c|c|c|c|c|c|c|c|c|c|c|}
\hline Sample ID & Dissolved & $\dot{H}_{\text {Hydrophobic }}^{+}$ & ${ }_{\text {Hydrophilic }}^{+}$ & $\begin{array}{c}>>20.000 \\
\frac{\mathrm{BIO}-}{\text { polymers }}\end{array}$ & $\begin{array}{c}\sim 1000 \text { (see } \\
\\
\text { Humic } \\
\text { Subst. } \\
\text { (HS) }\end{array}$ & $\begin{array}{c}\downarrow \\
\text { Aromaticity } \\
\text { (SUVA-HS) }\end{array}$ & $\underset{\substack{\text { Mol-Weight } \\
\overline{(M n)}}}{7}$ & $\begin{array}{c}300-500 \\
\\
\text { Building } \\
\text { Blocks }\end{array}$ & $\begin{array}{c}<350 \\
\frac{\hbar}{\text { LMW }} \\
\text { Neutrals }\end{array}$ & $\begin{array}{l}<350 \\
\downarrow \\
\text { LMW } \\
\text { Acids }\end{array}$ & $\begin{array}{c}\text { Inorganic } \\
\text { Colloids } \\
\text { SAC }\end{array}$ & $\begin{array}{c}\text { SUVA } \\
\text { (SAC/DOC) }\end{array}$ \\
\hline & $p p b-c$ & $p p b-c$ & $p p b-c$ & $p p b-c$ & $p p b-c$ & $L /\left(m^{*} m\right)$ & $\mathrm{g} / \mathrm{mol}$ & $p p b-c$ & $p p b-c$ & $p p b-c$ & $\left(m^{-1}\right)$ & $L\left(m^{\prime} m\right)$ \\
\hline & $\% \mathrm{DOC}$ & $\%$ DOC & $\%$ DOC & $\% \mathrm{DOC}$ & $\%$ DOC & - & - & $\% \mathrm{DOC}$ & $\%$ DOC & $\% \mathrm{DOC}$ & - & - \\
\hline \multirow[t]{2}{*}{ M1 } & 28974 & 533 & 28441 & 10921 & 9119 & 2.42 & 533 & 3248 & 5154 & n.q. & 19.34 & 2.18 \\
\hline & $100 \%$ & $1.8 \%$ & $98.2 \%$ & $37.7 \%$ & $31.5 \%$ & - & - & $11.2 \%$ & $17.8 \%$ & -- & - & - \\
\hline \multirow[t]{2}{*}{ M4 } & 19927 & 874 & 19053 & 4634 & 7883 & 2.26 & 556 & 2234 & 4301 & 1 & 17.87 & 2.62 \\
\hline & $100 \%$ & $4.4 \%$ & $95.6 \%$ & $23.3 \%$ & $39.6 \%$ & - & - & $11.2 \%$ & $21.6 \%$ & $0.0 \%$ & - & - \\
\hline \multirow[t]{2}{*}{ M7 } & 16985 & 1146 & 15840 & 5433 & 4898 & 2.72 & 468 & 2059 & 3449 & n.q. & 9.65 & 2.46 \\
\hline & $100 \%$ & $6.7 \%$ & $93.3 \%$ & $32.0 \%$ & $28.8 \%$ & - & - & $12.1 \%$ & $20.3 \%$ & -- & - & - \\
\hline \multirow[t]{2}{*}{ M10 } & 63657 & 4012 & 59644 & 31922 & 16665 & 1.98 & 500 & 4669 & 6388 & n.q. & 2.40 & 1.07 \\
\hline & $100 \%$ & $6.3 \%$ & $93.7 \%$ & $50.1 \%$ & $26.2 \%$ & - & - & $7.3 \%$ & $10.0 \%$ & -- & - & - \\
\hline \multirow[t]{2}{*}{ M11 } & 27577 & 2429 & 25147 & 10675 & 7476 & 1.66 & 469 & 2531 & 4466 & n.q. & 2.84 & 1.26 \\
\hline & $100 \%$ & $8.8 \%$ & $91.2 \%$ & $38.7 \%$ & $27.1 \%$ & - & - & $9.2 \%$ & $16.2 \%$ & -- & - & - \\
\hline
\end{tabular}




\section{Contents of Figure}

Figure 1: WARMS facility at Sydney Olympic Park

Figure 2: SEM images of hollow fibre PP membrane samples

Figure 3: Contact angle of hollow fibre membrane

Figure 4: Zeta potential of the hollow fibre membrane

Figure 5: Comparison of thermal degradation of PP hollow fibre membrane samples

Figure 6: FT-IR spectroscopy of PP hollow fibre membrane samples

Figure 7: LC-OCD chromatogram of a typical foulant sample extracted from the membrane fibres 


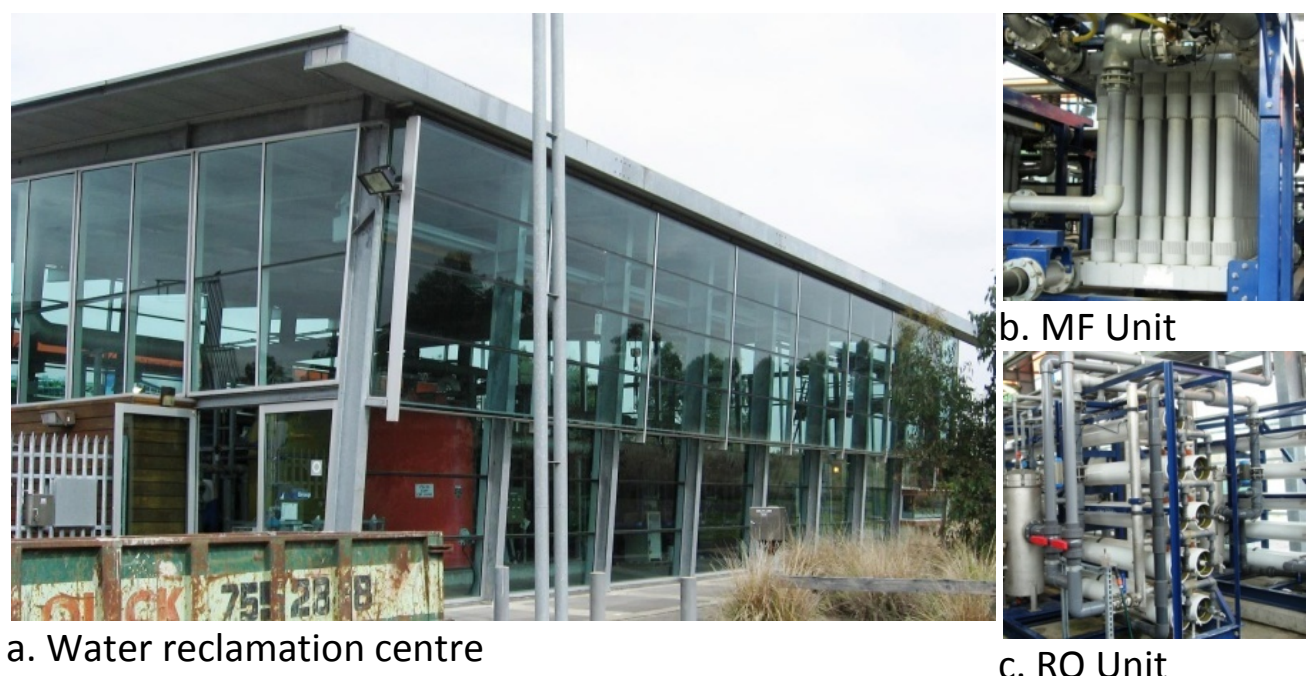

a. Water reclamation centre c. RO Unit

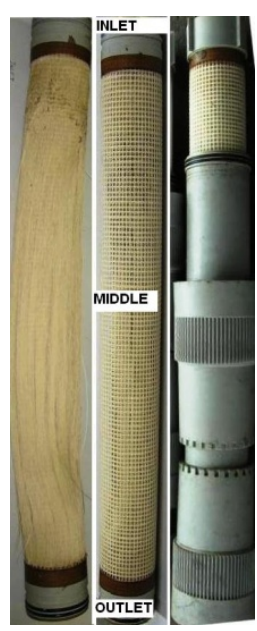

d. MF module sample

Figure 1: WARMS facility at Sydney Olympic Park 


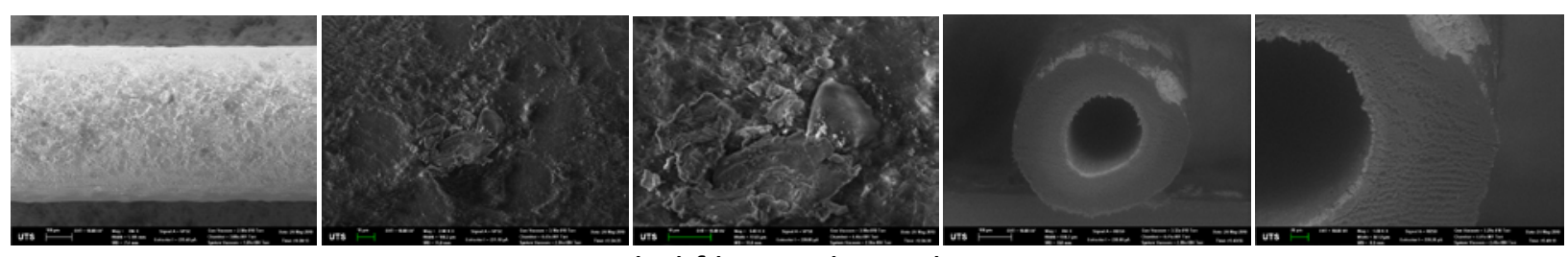

a. Fouled fibre without cleaning

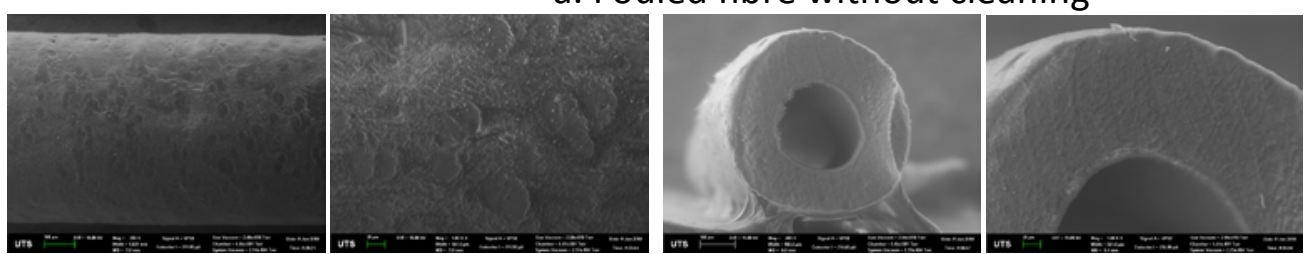

b. Fouled fibre after $0.1 \mathrm{~N} \mathrm{NaOH}$ and $\mathrm{HCl}$ cleaning
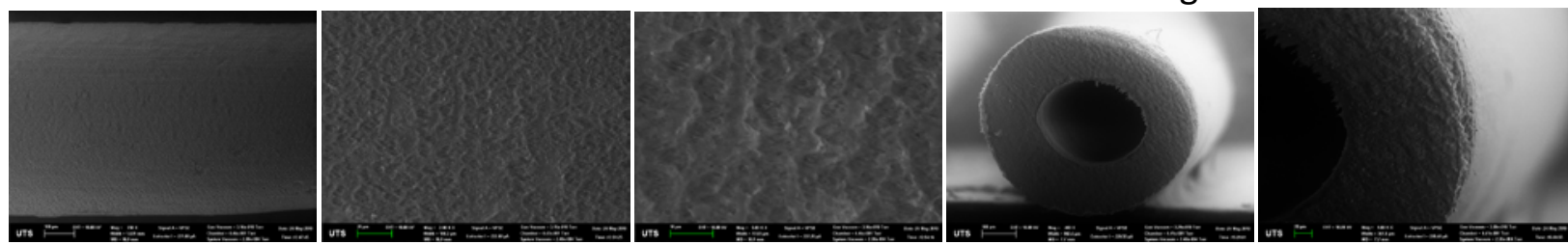

c. Virgin membrane

Figure 2: SEM images of hollow fibre PP membrane samples 


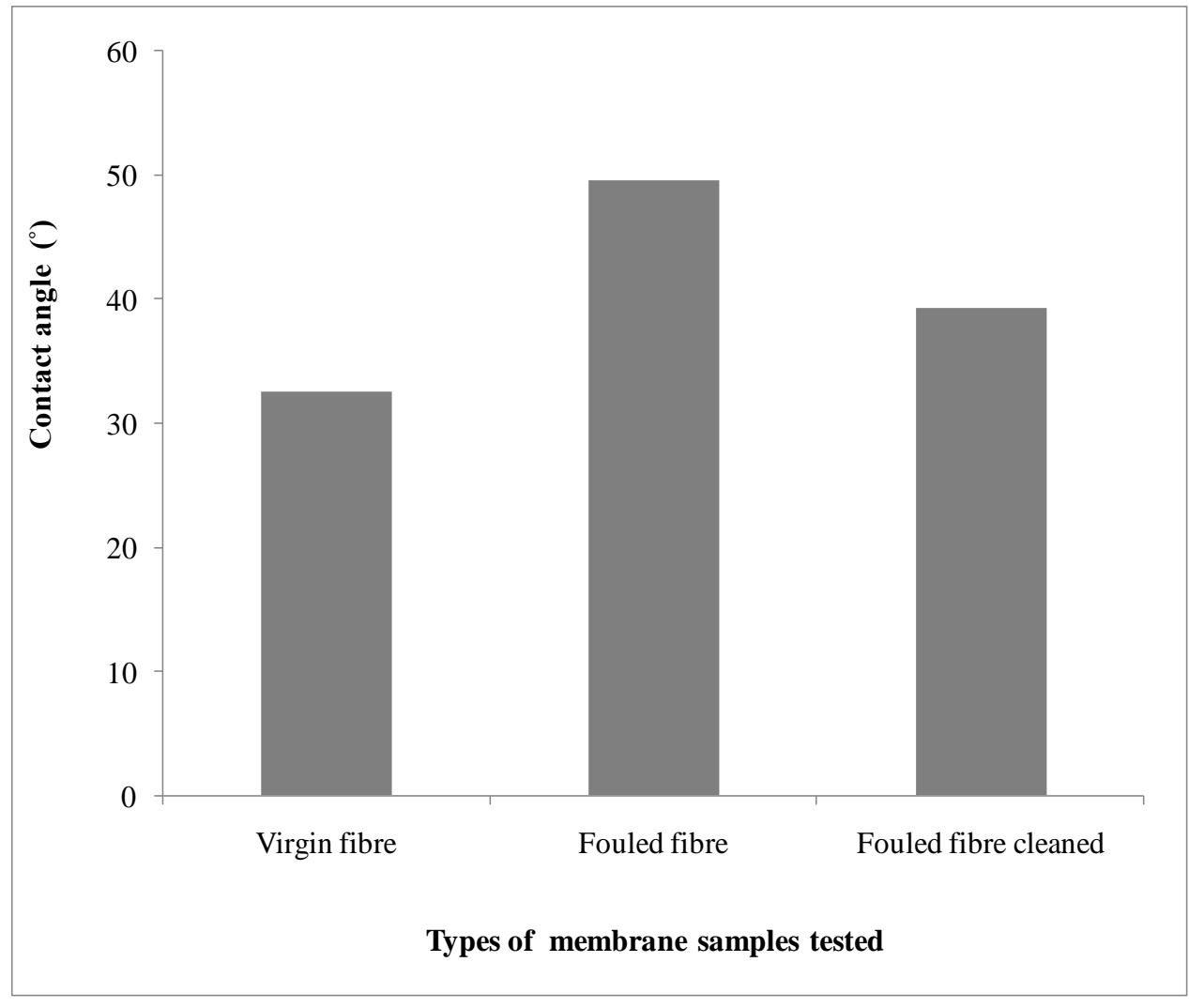

Figure 3: Contact angle of hollow fibre membrane 


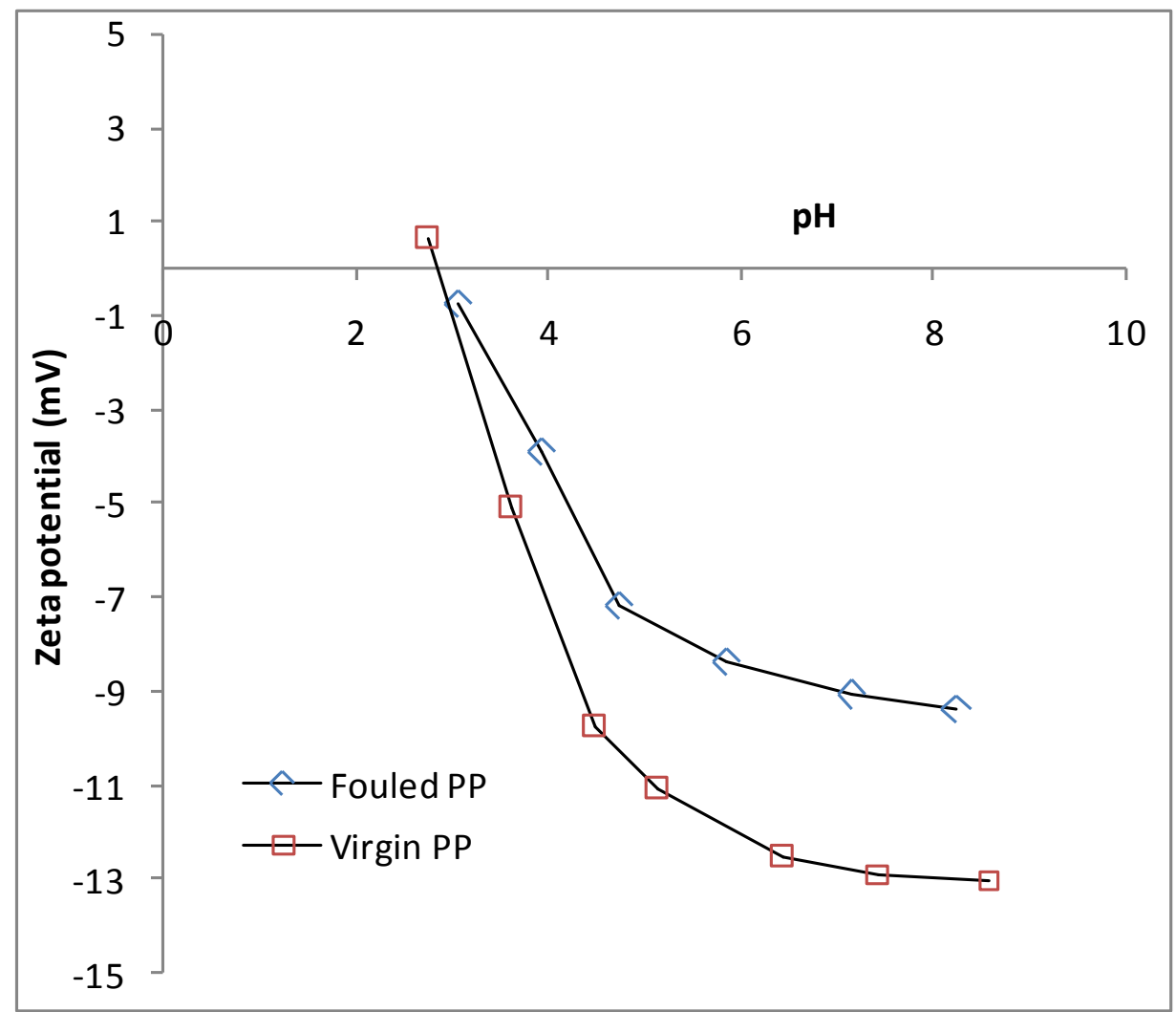

Figure 4: Zeta potential of the hollow fibre membrane 


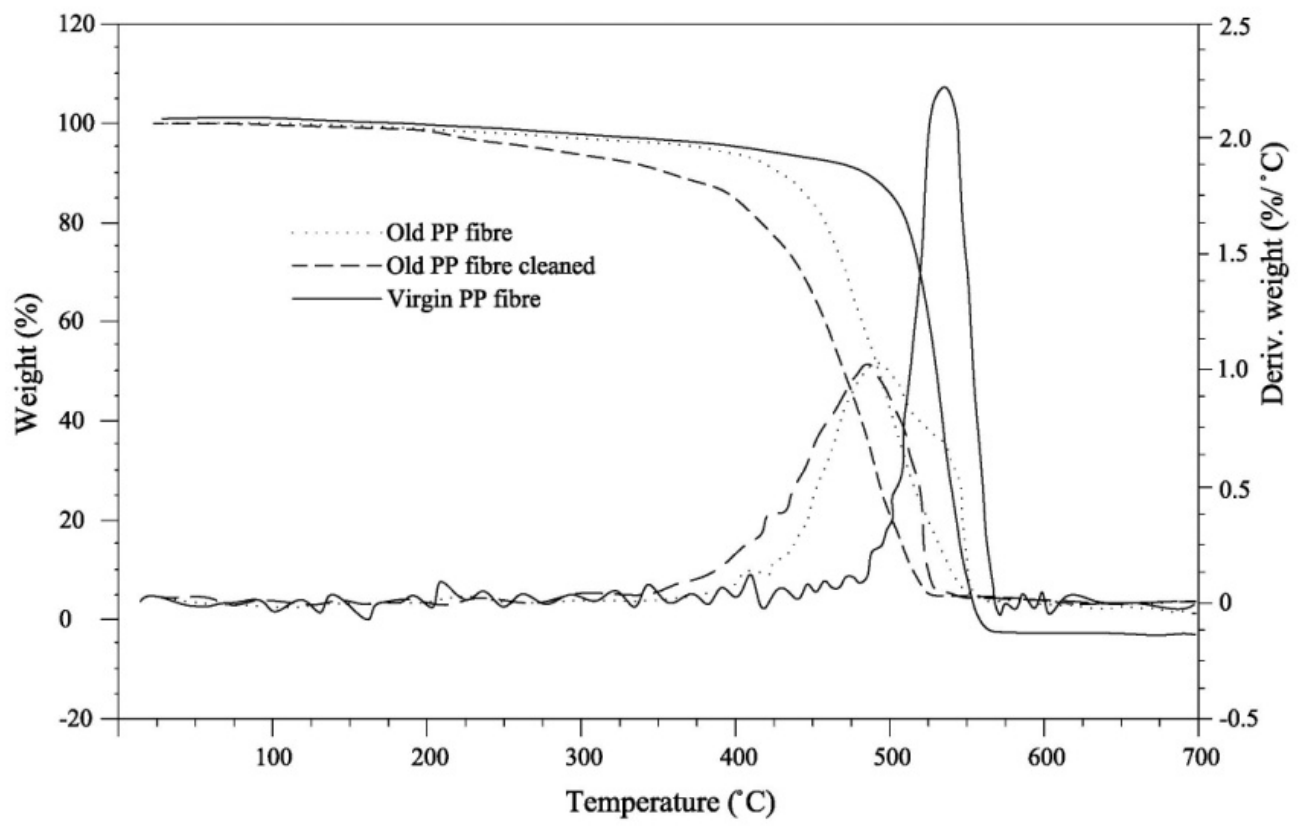

Figure 5: Comparison of thermal degradation of PP hollow fibre membrane samples 


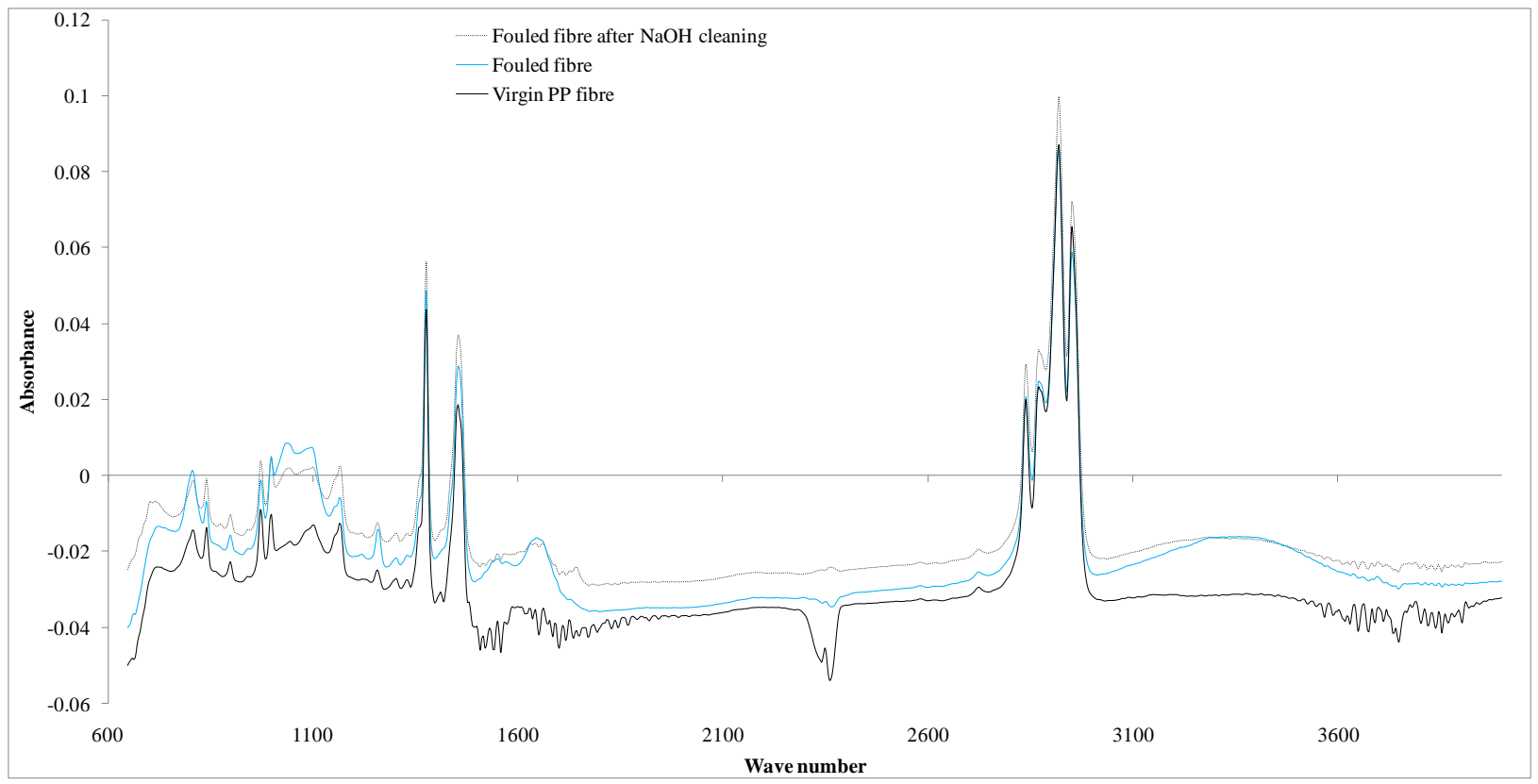

Figure 6: FT-IR spectroscopy of PP hollow fibre membrane samples 


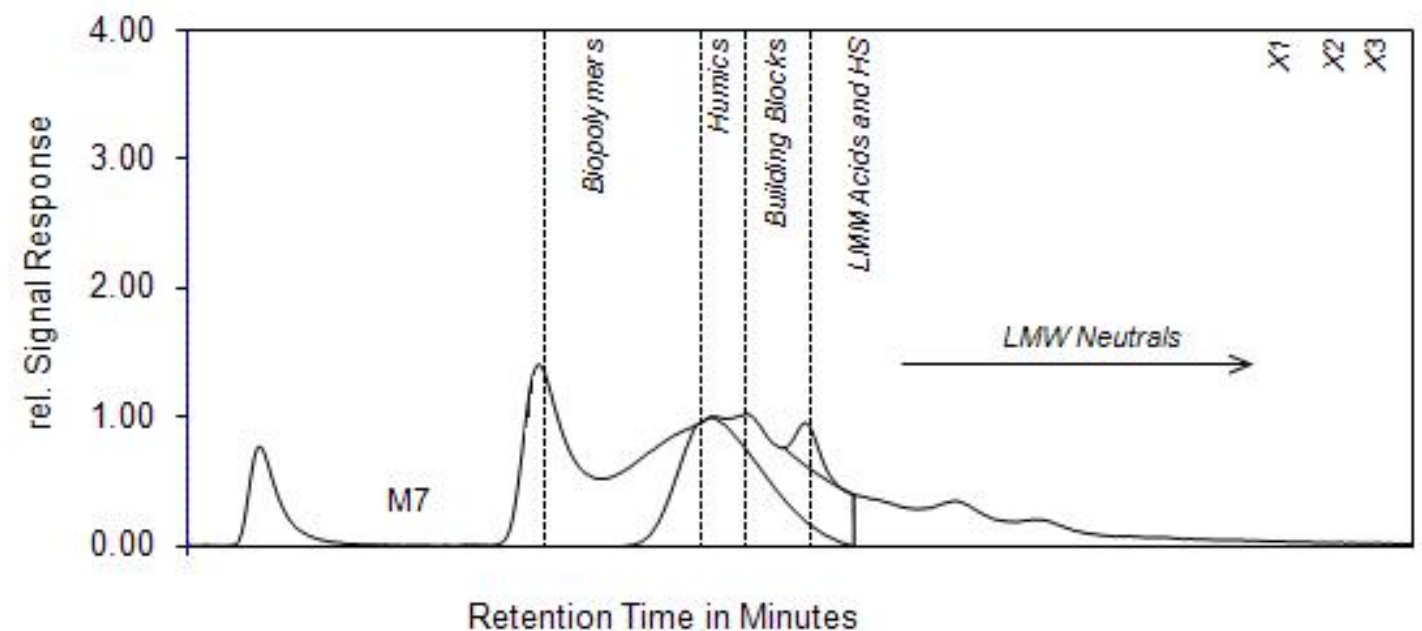

Figure 7: LC-OCD chromatogram of a typical foulant sample extracted from the membrane fibres 